\title{
Clinico-Demographic Characteristics of Tuberculous Lymphadenitis: Experience of 50 Cases in Bangladesh
}

\author{
Mohammad Mahmudul Huda', Mohammad Taufiq², Md. Abdullah Yusuf ${ }^{3}$, \\ Mohammad Rezwanur Rahman4, Ferdousy Begum5, Mohammed Kamal5 \\ ${ }^{1}$ Department of Pathology, Dhaka National Medical College, Dhaka, Bangladesh \\ ${ }^{2}$ Square Hospital, Dhaka, Bangladesh \\ ${ }^{3}$ Department of Microbiology, National Institute of Neurosciences \& Hospital, Dhaka, Bangladesh \\ ${ }^{4}$ Department of Biochemistry, Delta Medical College, Dhaka, Bangladesh \\ ${ }^{5}$ Department of Pathology, Banghabandhu Sheikh Mujib Medical University, Dhaka, Bangladesh \\ Email: mmhuda.himel@gmail.com, susanbd71@hotmail.com, ayusuf75@yahoo.com,rezwanrahman5@yahoo.com, \\ ferdousy_begum2000@yahoo.com,kamalzsr@yahoo.com
}

How to cite this paper: Huda, M.M., Taufiq, M., Yusuf, Md.A., Rahman, M.R., Begum, F. and Kamal, M. (2016) ClinicoDemographic Characteristics of Tuberculous Lymphadenitis: Experience of 50 Cases in Bangladesh. Journal of Tuberculosis Research, 4, 220-226.

http://dx.doi.org/10.4236/jtr.2016.44024

Received: November 25, 2016

Accepted: December 19, 2016

Published: December 22, 2016

Copyright $\odot 2016$ by authors and Scientific Research Publishing Inc. This work is licensed under the Creative Commons Attribution International License (CC BY 4.0).

http://creativecommons.org/licenses/by/4.0/ (c) (i) Open Access

\section{Abstract}

Background: Clinical and demographic features are important for the tuberculous lymphadenitis patients for treatment. Objective: The purpose of the present study was to see the clinical and demographic features of tuberculous lymphadenitis patients. Methodology: This cross-sectional study was done at the Department of Pathology at Banghabandhu Sheikh Mujib Medical University (BSMMU), Dhaka from January 2009 to March 2011 for a period of nearly two years. All the patients, irrespective of age and sex with the clinical features, suggestive of tuberculous lymphadenitis and later on, proved to be the same histologically, were selected for the study purposively. Relevant information was recorded in a prescribed data sheet and histomorphological findings were recorded accordingly. In cases where fresh specimen was available, caseous portion of lymph node was sent for culture. Fite Faraco staining was also done on lymph node sections in all cases. Result: A total number of 50 tuberculous lymphadenitis patients were recruited for this study. Among this study population, the age of cases ranged from 12 years to 65 years with a mean age of $26.22 \pm 2.52$ years. Male and female ratio was 1:1.38. Besides lymphadenopathy, 45 patients had low grade fever; 32 patients had weight loss and 18 patients had cough. Among 50 cases of lymph node tuberculosis cervical lymphadenopathy was 41 (82.0\%) cases; 6 (12.0\%) cases had supraclavicular lymphadenopathy; 2 (4.0\%) cases had inguinal lymphadenopathy and 1 (2.0\%) had axillary lymphadenopathy. The mean duration of presentation of lymphadenopathy with standard deviation was $7.06 \pm 1.6$ months. 
Thirty eight patients (76.0\%) had lymphadenopathy for less than 12 months. Conclusion: In conclusion, young age group people are most commonly affected by tuberculous lymphadenitis with the predominance of female and most of them are presented with low grade fever and weight loss.

\section{Keywords}

Tuberculous Lymphadenitis, Tuberculosis, Lymph Nodes, Clinical Features

\section{Introduction}

Lymph nodes are usually involved in the early stages of the pulmonary disease or as secondary TB by hematogenous spread [1]. However, tuberculous lymphadenitis may arise without a detectable preceding pulmonary involvement [2]. Tuberculous lymphadenitis affects mainly the cervical lymph node group and is an important cause of lymphadenopathy worldwide [3]. The clinical as well as the demographic characteristics are varied. To confirm the cases, histopathological examination or FNAC is needed. These help to arrive at an early diagnosis of tubercular lymphadenitis and institution of treatment before a final diagnosis is made by culture [4]. Histopathological examination is suggestive of tuberculous lymphadenitis where Langhans' giant cells, caseation necrosis, coalescing granuloma are present. The physicians treat these cases with anti-tubercular chemotherapy. In cases which are reported as "suggestive of tuberculosis", the physician needs additional features such as positive Mantoux test and clinical symptoms to start anti-tubercular chemotherapy. Therefore, the clinical as well as the demographics profiles are important for the treatment of tuberculous lymphadenitis. In this context, the present study was undertaken to see the clinico-demographic characteristics of tuberculous lymphadenitis.

\section{Methodology}

This cross sectional study was done at the Department of Pathology at Banghabandhu Sheikh Mujib Medical University (BSMMU), Dhaka from January 2009 to March 2011 for a period of nearly two years. All the patients irrespective of age and sex with the clinical features suggestive of tuberculous lymphadenitis and later on proved to be the same histologically were selected for the study purposively. The patients without having history of anti-tubercular drugs, malignancy and symptoms other than TB were excluded from this study. Relevant information was recorded in a prescribed data sheet and histomorphological findings were recorded accordingly. In cases where fresh specimen was available, caseous portion of lymph node was sent to ICDDRB for culture in conventional egg based Lowenstein-Jensen medium. This part was done maintaining high level of sterility. Ziehl-Neelsen stain was done in smear prepared from 20 fresh cases. Fite Faraco staining was also done on lymph node sections in all cases. Computer based statistical analysis was carried out with appropriate techniques and systems. All 
data were recorded systematically in preformed data collection form (questionnaire) and quantitative data were expressed as mean and standard deviation and qualitative data were expressed as frequency distribution and percentage. Statistical analysis was performed by using window based computer software devised with Statistical Packages for Social Sciences (SPSS-22.0) (SPSS Inc, Chicago, IL, USA). 95\% confidence limit was taken. The summarized data was interpreted accordingly and was then presented in the form of tables figures.

\section{Results}

A total number of 50 tuberculous lymphadenitis patients were recruited for this study. Among this study population the age of cases ranged from 12 years to 65 years with a mean age of $26.22 \pm 2.52$ years. Maximum number of patients $(n=21)$ were found in the age group of $21-30$ (Table 1 ).

In this study there were $21(42.0 \%)$ male and 29 (58.0\%) female patients. Male female ratio was 1:1.38 (Table 2).

Besides lymphadenopathy 45 patients had low grade fever, 32 patients had weight loss and 18 patients had cough (Figure 1).

Among 50 cases of lymph node tuberculosis 41 (82.0\%) cases had cervical lymphadenopathy, 6 (12.0\%) cases had supraclavicular lymphadenopathy, 2 (4.0\%) cases had inguinal lymphadenopathy and 1 (2.0\%) had axillary lymphadenopathy. One case had both cervical and inguinal lymphadenopathy (Figure 2).

The mean duration of presentation of lymphadenopathy with standard deviation was $7.06 \pm 1.6$ months. Thirty eight patients $(76.0 \%)$ had lymphadenopathy for less than 12 Months. Rest of the patients (24.0\%) suffered for more than 12 Months. Duration of

Table 1. Different age groups of the study population.

\begin{tabular}{ccc}
\hline Age (years) & Frequency & Percentage \\
\hline $11-20$ & 16 & 32 \\
$21-30$ & 21 & 42 \\
$31-40$ & 7 & 14 \\
$41-50$ & 4 & 8 \\
$51-60$ & 1 & 2 \\
$>60$ & 1 & 2 \\
Total & 50 & 100.0
\end{tabular}

Table 2. Gender distribution of the study population.

\begin{tabular}{ccc}
\hline Gender & Frequency & Percentage \\
\hline Male & 21 & 42.0 \\
Female & 29 & 58.0 \\
Total & $\mathbf{5 0}$ & $\mathbf{1 0 0 . 0}$ \\
\hline
\end{tabular}




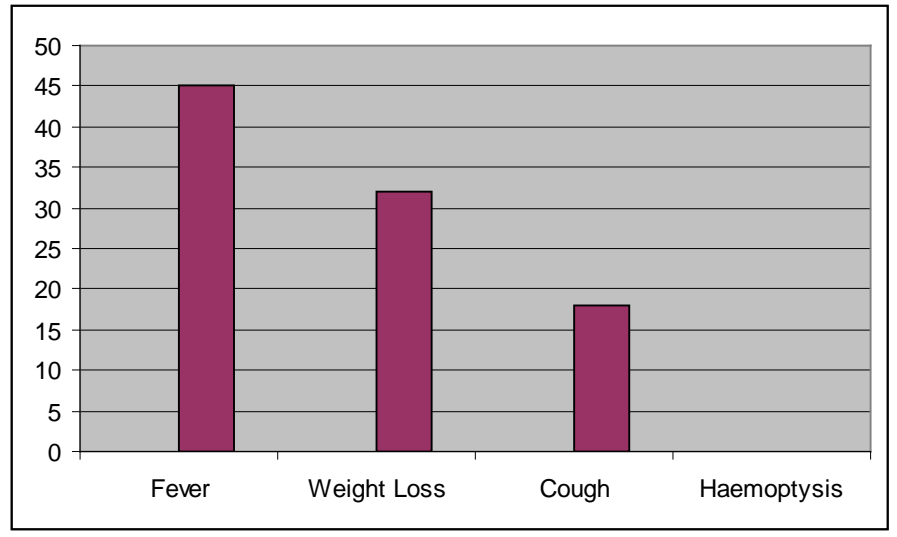

Figure 1. Showing clinical presentation of study population.

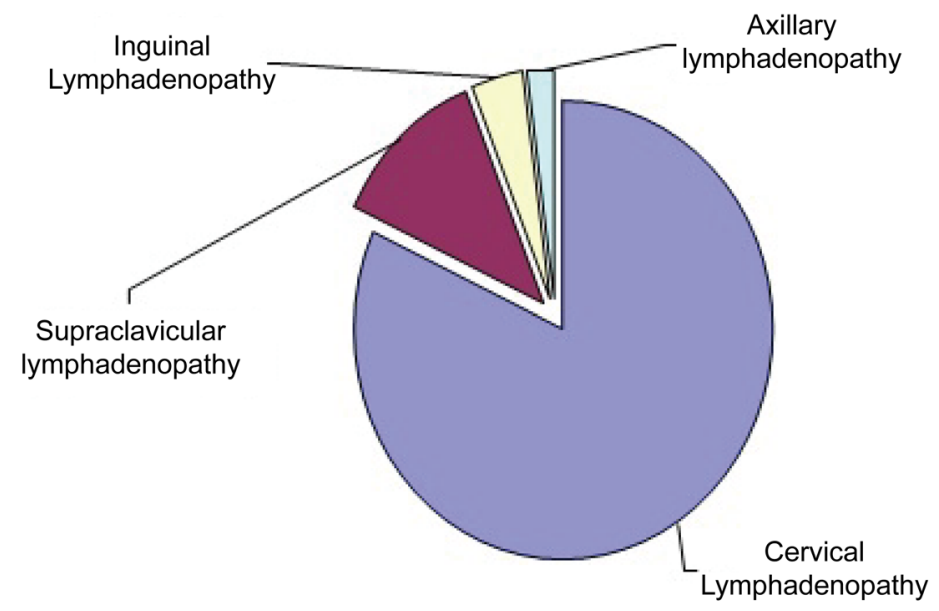

Figure 2. Distribution of lymphadenopathy among the study population.

symptoms ranges from 2 months to 13 months. Mean duration of symptoms was 7.06 months (Table 3).

\section{Discussion}

Someone in the world is newly infected with TB bacilli every second. Overall, one-third of the world's population is currently infected with the TB bacillus [5]. Among the various diagnostic tools of tubercular lymphadenitis histological diagnosis is an important one. As the morphological features are variable this descriptive study was performed in 50 cases of tubercular lymphadenitis to find out histomorphological features and correlate with clinical profile and treatment outcome. Among the 50 cases age range was 12 to 65 years with the mean age of $26.22 \pm 2.52$ years. Highest number of cases was found in 21 - 30 years age groups (42.0\%) followed by $11-20$ years (32.0\%). Studies performed found majority of cases in adolescents and young females reflecting similar features [6] [7]. Male to female ratio in this present study is 1:1.38. Other studies found ratio close to the present study such as Dandapat et al. [8] 1:1.2 and Jha et al. [9] 1:1.3. Female have low nutritional status in a socioeconomic structure that is present in this 
subcontinent and are vulnerable to clinical TB.

This study was carried on superficial lymph node TB. Of them $82.0 \%$ cases had cervical lymphadenopathy, $12.0 \%$ had supraclavicular lymphadenopathy, $4.0 \%$ had inguinal lymphadenopathy and $2.0 \%$ had axillary lymphadenopathy. In addition to the swelling, most of the patients of the present study had constitutional symptoms like 90.0\% had low grade fever, $64.0 \%$ had weight loss and 36.0\% had cough. Dandapat et al. [8] and Pahwa et al. [10] observed fever in $40.0 \%$ cases while in another study it has been found that fever is present in $73.0 \%$ cases which is similar to the present study. In case of weight loss Dandapat et al. [8] found weight loss in $85 \%$ cases while Patel and Mehta [11] observed weight loss in $77.0 \%$ cases. Pahwa et al. [10] observed cough in 23.0\% cases. Though most of the studies [12]-[19] found high rate of cervical lymphadenopathy, it is higher in the present study. Mantoux test results are similar with other studies. Raised ESR was found in $84.0 \%$ cases in the present study whereas Jha et al. [9] found $92.86 \%$ in their study (Table 4 ).

Duration of symptoms ranged from 2 months to 13 months with mean duration of 7.06 months. Jha et al. [8] found mean duration of symptoms during presentation was 3 months. Probably patients of this country present to the physician at later stage of disease due to ignorance or other social stigma.

Tuberculous lymphadenitis usually presents as a slowly progressive, painless swelling of a single group of lymph nodes. The duration of symptoms at the time of presentation is typically $1-2$ months, varying from 3 weeks to 8 months. In a series of patients, the mean duration of symptoms was significantly longer in men than in women [20].

Table 3. Duration of presentation of lymphadenopathy of the studied population.

\begin{tabular}{ccc}
\hline Duration & Frequency & Percentage \\
\hline Less than 12 months & 38 & 76.0 \\
More than 12 months & 12 & 24.0 \\
Total & $\mathbf{5 0}$ & $\mathbf{1 0 0 . 0}$ \\
\hline
\end{tabular}

${ }^{\star}$ Mean $\pm \mathrm{SD}=7.06 \pm 1.6$.

Table 4. Comparison of clinical feature between different study and present study.

\begin{tabular}{ccccccccc}
\hline & M:F & $\begin{array}{c}\text { Cervical } \\
\text { LN }\end{array}$ & $\begin{array}{c}\text { Axillary } \\
\text { LN }\end{array}$ & $\begin{array}{c}\text { Inguinal } \\
\text { LN }\end{array}$ & $\begin{array}{c}\text { Raised } \\
\text { ESR }\end{array}$ & MT & Fever & $\begin{array}{c}\text { Weight } \\
\text { Loss }\end{array}$ \\
\hline Patel and Mehta [11] & $1: 1.6$ & $77 \%$ & & & & $80 \%$ & & \\
Dandapat et al. [8] & $1: 1.2$ & $85 \%$ & $6.25 \%$ & $8.75 \%$ & & $74 \%$ & $40 \%$ & $85 \%$ \\
$\quad$ Jha et al. [9] & $1: 1.3$ & $87.50 \%$ & $8.93 \%$ & $3.57 \%$ & $92.86 \%$ & $94.64 \%$ & $18 \%$ & $14 \%$ \\
Pahwa et al. [10] & $1: 1.33$ & $89 \%$ & $9 \%$ & $2 \%$ & & & $40 \%$ & \\
Present study & $1: 1.3$ & $94 \%$ & $2 \%$ & $4 \%$ & $84 \%$ & $74 \%$ & $90 \%$ & $64 \%$ \\
\hline
\end{tabular}




\section{Conclusion}

In conclusion, young age group is most commonly affected by tuberculous lymphadenitis with the predominance of female. Furthermore, most of them are presented with low grade fever and weight loss. Cervical lymphadenopathy is the most common site of involvement of tuberculous lymphadenitis.

\section{References}

[1] Murray, C.J., Styblo, K. and Rouillon, A. (1990) Tuberculosis in Developing Countries: Burden, Intervention and Cost. Bulletin of the International Union Against Tuberculosis and Lung Disease, 65, 6-24.

[2] Kumar, V., Abbas, A.K., Fausto, N. and Aster, J.C. (2014) Robbins and Cotran Pathologic Basis of Disease. Elsevier Health Sciences, 27 August.

[3] Seth, V., Kabra, S.K., Jain, Y., Semwal, O.P., Mukhopadhyaya, S. and Jensen, R.L. (1995) Tubercular Lymphadenitis: Clinical Manifestations. Indian Journal of Pediatrics, 62, 565570. https://doi.org/10.1007/BF02761878

[4] Chaisson, R.E., Schecter, G.F., Theuer, C.P., Rutherford, G.W., Echenberg, D.F. and Hopewell, P.C. (1987) Tuberculosis in Patients with the Acquired Immunodeficiency Syndrome: Clinical Features, Response to Therapy, and Survival. American Review of Respiratory Disease, 136, 570-574. https://doi.org/10.1164/ajrccm/136.3.570

[5] Raviglione, M.C., Narain, J.P. and Kochi, A. (1992) HIV-Associated Tuberculosis in Developing Countries: Clinical Features, Diagnosis, and Treatment. Bulletin of the World Health Organization, 70, 515.

[6] Artenstein, A.W., Kim, J.H., Williams, W.J. and Chung, R.C. (1995) Isolated Peripheral Tuberculous Lymphadenitis in Adults: Current Clinical and Diagnostic Issues. Clinical Infectious Diseases, 20, 876-882. https://doi.org/10.1093/clinids/20.4.876

[7] Chao, S.S., Loh, K.S., Tan, K.K. and Chong, S.M. (2002) Tuberculous and Nontuberculous Cervical Lymphadenitis: A Clinical Review. Otolaryngology_Head and Neck Surgery, 126, 176-179. https://doi.org/10.1067/mhn.2002.121912

[8] Dandapat, M.C., Mishra, B.M., Dash, S.P. and Kar, P.K. (1990) Peripheral Lymph Node Tuberculosis: A Review of 80 Cases. British Journal of Surgery, 77, 911-912.

https://doi.org/10.1002/bjs.1800770823

[9] Jha, B.C., Dass, A., Nagarkar, N.M., Gupta, R. and Singhal, S. (2001) Cervical Tuberculous Lymphadenopathy: Changing Clinical Pattern and Concepts in Management. Postgraduate Medical Journal, 77, 185-187. https://doi.org/10.1136/pmj.77.905.185

[10] Pahwa, R., Hedau, S., Jain, S., Jain, N., Arora, V.M., Kumar, N. and Das, B.C. (2005) Assessment of Possible Tuberculous Lymphadenopathy by PCR Compared to Non-Molecular Methods. Journal of Medical Microbiology, 54, 873-878. https://doi.org/10.1099/jmm.0.45904-0

[11] Patel, R.V. and Mehta, R.T. (1987) Short Term Chemotherapy in Tuberculous Lymphadenitis. Indian Journal of Surgery, 49, 336-341.

[12] Fontanilla, J.M., Barnes, A. and Von Reyn, C.F. (2011) Current Diagnosis and Management of Peripheral Tuberculous Lymphadenitis. Clinical Infectious Diseases, 53, 555-562. https://doi.org/10.1093/cid/cir454

[13] Swaminathan, S. and Rekha, B. (2010) Pediatric Tuberculosis: Global Overview and Challenges. Clinical Infectious Diseases, 50, S184-S194. https://doi.org/10.1086/651490 
[14] Graham, S.M., Ahmed, T., Amanullah, F., Browning, R., Cardenas, V., Casenghi, M., Cuevas, L.E., Gale, M., Gie, R.P., Grzemska, M. and Handelsman, E. (2012) Evaluation of Tuberculosis Diagnostics in Children: 1. Proposed Clinical Case Definitions for Classification of Intrathoracic Tuberculosis Disease. Consensus from an Expert Panel. Journal of Infectious Diseases, 205, S199-S208. https://doi.org/10.1093/infdis/jis008

[15] Nidhi, P., Sapna, T., Shalini, M. and Kumud, G. (2011) FNAC in Tuberculous Lymphadenitis Experience from a Teritiary Level Referral Centre. Indian Journal of Tuberculosis, 58, 102-107.

[16] Derese, Y., Hailu, E., Assefa, T., Bekele, Y., Mihret, A., Aseffa, A., Hussien, J., Ali, I. and Abebe, M. (2011) Comparison of PCR with Standard Culture of Fine Needle Aspiration Samples in the Diagnosis of Tuberculosis Lymphadenitis. Journal of Infection in Developing Countries, 6, 53-57.

[17] Sia, I.G. and Wieland, M.L. (2011) Current Concepts in the Management of Tuberculosis. Mayo Clinic Proceedings, 86, 348-361. https://doi.org/10.4065/mcp.2010.0820

[18] Sathekge, M., Maes, A., D’Asseler, Y., Vorster, M., Gongxeka, H. and Van de Wiele, C. (2012) Tuberculous Lymphadenitis: FDG PET and CT Findings in Responsive and Nonresponsive Disease. European Journal of Nuclear Medicine and Molecular Imaging, 39, 1184-1190. https://doi.org/10.1007/s00259-012-2115-y

[19] Ahmed, H.G., Nassar, A.S. and Ginawi, I. (2011) Screening for Tuberculosis and Its Histological Pattern in Patients with Enlarged Lymph Node. Pathology Research International, 2011, Article ID: 417635. https://doi.org/10.4061/2011/417635

[20] Iqbal, M.A., Subhan, A.N. and Aslam, A.S. (2010) Frequency of Tuberculosis in Cervical Lymphadenopathy. Journal of Surgery Pakistan, 15, 107-109.

\section{Submit or recommend next manuscript to SCIRP and we will provide best service for you:}

Accepting pre-submission inquiries through Email, Facebook, LinkedIn, Twitter, etc.

A wide selection of journals (inclusive of 9 subjects, more than 200 journals)

Providing 24-hour high-quality service

User-friendly online submission system

Fair and swift peer-review system

Efficient typesetting and proofreading procedure

Display of the result of downloads and visits, as well as the number of cited articles

Maximum dissemination of your research work

Submit your manuscript at: http://papersubmission.scirp.org/

Or contact jtr@scirp.org 